\title{
CORRESPONDENCE
}

\section{Psychological slip}

SIR - Reviewing H.B. Gibson's biography of Hans Eysenck (Nature 5 November, p.44) P.E. Bryant writes: "He (Eysenck), more than anyone, shaped the development of clinical psychology in this country".

This statement may be misleading to a readership as diverse as Nature's. In this context the term "clinical psychology" is used, or perhaps linguistically corrupted, to signify the application of behaviouristic or learning theories to the treatment of psychological disorders. It does not refer to the application of psychological theories collectively to the treatment of such disorders, which is the rational inference.

It may well be the case that Eysenck has shaped the development of behaviouristic clinical psychology in this country. However, it would clearly be incorrect to suggest that he has had much influence on the development of certain other principal approaches to clinical psychology such as psychoanalysis.

This duality of meaning is a potential source of considerable confusion, but one which can be simply obviated by qualifying the specific school of clinical psychology referred to.

\section{George Fieldman}

Department of Physiology,

Chelsea College, London SW3

\section{Species difference}

SIR - There is a serious misunderstanding which is impeding any resolution to the current debate on macroevolution. Recent analysts of the fossil record report a pattern which they claim "strongly supports the notion that speciation is a qualitatively different phenomenon from gradual, intraspecific microevolutionary change"'. This is true. Others point out that the observed details of fossil history "do not force us to change our views on the genetic mechanisms of the origin of species"2. This is also true. The misunderstanding lies in the idea that they are referring to the same thing, for they are not. They are addressing speciation on two entirely different levels.

The model of evolution in contention is the "punctuated equilibrium" proposal of Eldredge and Gould ${ }^{3}$. Evolution at the specific level is seen as occurring in short rapid bursts followed by relatively long periods of evolutionary non-change or stasis. The words "short" and "long" are used in the context of geological time. That is, morphological changes associated with the transition from an old species to a new one may occur on the order of $10^{3}$ to $10^{4}$ years, which is recorded as an instant in most fossil assemblages. Those who experiment on the evolutionary genetics of living organisms are quite correct in maintaining that this is more than enough time for classical selection mechanisms to have conceivably produced the observed changes. This much is clear to proponents of punctuated equilibrium as well. Why then the call for qualitatively new explanations?

The mechanisms depicting "how" new species arise have in the past been considered explanations of "why" they develop as well. New species are classically described as being the logical result of long, slow, continuous selective pressure. This continual change is the view of phyletic gradualism. If, however, the prevailing pattern is one of stable equilibrium only punctuated with brief periods of evolutionary change then the mechanism of that change does not tell the whole story. The phenomenon of stasis, not the sudden appearance of new species, is the true source of the conflict with the traditional evolutionary school of thought.

Matters are not reconciled by appealing to selective pressures varying dramatically over time. The environment is dynamic and in a constant state of flux. While some periods may be characterized by a less stable climate than others, there are always marginal environments and isolated communities within which evolution can work. In addition the fossil record does not support the contention that novel stable species arise and replace parental populations only at times of the most extraordinary environmental instability. That is not to say that new species do not arise at times of climatic shifts, but other shifts of equal magnitude may not result in the establishment of new species while novel forms may invade from a marginal locale and become dominant at times of overall relative environmental tranquillity. Thus classical Darwinian theory does not provide an explanation for the punctuated pattern of speciation now emerging from the fossil record.

The models of population genetics may be perfectly adequate at the fine level of how new genetic entities are formed but they do not address questions at the grosser level of the overall patterns. New qualitatively different schemes are therefore needed. Conversely, while theories of a qualitatively different sort are indeed required by the recent reevaluations of the fossil record, the classical genetic mechanisms of speciation are nonetheless compatible with punctual equilibrium.

ClifF TABIN

Massachusetts Institute of Technology, Cambridge, Massachusetts, USA

1. Williamson, P.G. Nature 293, 437-443 (1981).

2. Jones, J.S. Nature 293, 427-428 (1981)

3. Eldredge, N. \& Gould, S.J. Models in Paleobiology (ed. Schopf, T.J.M.) (Freeman, San Francisco, 1972).

\section{Question of faiths}

SIR - It is admirable to see scientists such as A.H. Batten and E.W. MacKie (Nature 30 July, p.402) come to the aid of the theory of evolution when they perceive that it is threatened by creationism. Such enthusiasm shows their dedication to rational thought. However, when in their eagerness they instead misrepresent its basic scientific tenets one has to wonder just whose side they are on.

Batten is quite correct in criticizing neoDarwinian evolutionists for being overly dogmatic and thus in fact hastening the rise of the creationist movement. I cannot accept, however, the assertion that the theory of evolution (that is, descent with modification) is the same as the theory of natural selection and, therefore, if chance mutations are found to be insufficient agents of phylogenetic change one must look for a purposive element to explain the observed hierarchical order in nature. This self-imposed dichotomy leads Batten to reject Popper's critical rationalism for Kuhn's paradigm of "normal science".

We are thus asked to console ourselves with knowing that if we wish to avoid a dogmatic assertion of evolution as a fact then it is necessary to see it as simply the best explanation we have at the moment. Since we must choose between neo-Darwinism and creationism there is not much chance of ever escaping the bonds of the existing paradigm. Batten's complacency with "normal science" and inability to consider other, natural causative agents of evolutionary change (of which the literature is full) only serve to weaken any intended appeal to reason. The arguments presented are also a serious misrepresentation of Popper's philosophy.

MacKie, on the other hand, has chosen to ignore Popper or any other proponent of the hypothetico-deductive method altogether (ignorance of this concept is difficult to believe) and take us almost 400 years into the past. The notion of science as inductive and mythology as deductive might have impressed Francis Bacon, but it has no place in modern thought. Someone should tell MacKie about David Hume. The only way out of the conundrum is to realize that science arises from grand, explanatory ideas, ranging from the metaphysical to the conjectural, and it is only after this initial synthesis that rigid testing is invoked. It is the creationists' uncritical appraisal of their own theories, in both testing procedures and methods of formulation, that marks their endeavours as unscientific. The inductive-deductive barrier has nothing to do with it.

Both authors should learn to live with Popper's observation that rational thought is based on irrational faith in reason. I would add that evolutionary biology is similarly based on a faith that the natural causes we observe are indeed natural causes, and not the manifestations of a supernatural being. We are, then, faced with two faiths: those of rationality and irrationality. The former we can modify with critical argument, the latter we cannot. Yet, just because rationality arises from an irrational faith, we are not compelled to consider every aspiring scientific argument on equal grounds. It is not a case of the "anything goes" attitude of relativism. I believe that is what MacKie worried about as egalitarianism. There should be no problem, since every hypothesis must prove itself in its explanatory power, testability and predictive success. Thus, as MacKie notes, the acceptance procedure for hypotheses must be shamelessly elitist (with respect to the particular hypothesis, not its proponent). Anything less would be uncritical and therefore unscientific. Faith per se is no threat to science; dogma and woolly-mindedness are.

Richard T. O'Grady

Department of Zoology,

University of British Columbia,

Vancouver, Canada 